of clinical practice. The examiners who are not trained 'in this way', having their own idiosyncrasies, are quick to penalize anything contrary to their personal tastes. Many trainees lack basic skills and the standard of psychiatry remains very low in some hospitals. They urge that something should be done so that the forms Clinical Tutors sign to say that a trainee is ready to take the examination have some meaning.

May I ask them on which population they have based their findings? Perhaps it is those to whom APIT tried to teach 'the content of the mental state'. In May ' 78 out of 210 candidates 109 passed and in November '78 out of 251 candidates 134 passed the M.R.C.Psych. examination. I wonder how they will explain this pass rate in spite of the appalling training and the idiosyncrasies of the examiners? Or could they tell us from their own personal experiences whether their standard of clinical practice has suffered because of their taking the examination? Constructive suggestions are conspicuous by their absence in their letter. Apart from demanding clarifications to the examination protocols, they seem to have resigned themselves to the state of affairs of 'appalling training' and 'the lowering of the standards of clinical practice'.

While refusing to take the pessimistic view that the whole system is falling apart, I should point out that there is room for improvement in the training provided to the candidates especially in the peripheral hospitals. As one who has gone through the mill, I can say that, given more training and opportunities all through the year to sharpen his performance in examining and presenting a case for formulation and critical appraisal, the candidate would gain far more than by attending a workshop at the last moment where the numerous tips offered help only to add to the confusion.

The College could help by promoting closer coordination between Inceptors, Clinical Tutors and the Panel of Examiners, so that the examiners pass on their views and comments following each examination to the Inceptors through the Tutors. The Tutors could consider inviting the examiners to give their trainees practical training in the form of periodic mock examinations, etc., which is not an unrealistic proposition considering that there were more than 70 examiners on the panel at the last count. There should be an active campaign for recruitment for Inceptors and regional scientific meetings geared solely to their needs, so that the organization does not seem distant to them or insensitive to their requirements.

D. P. SRinivasan

Metabolic Research Unit,

High Royds Hospital,

Menston, West Yorks.

\section{DO YOUR SCHIZOPHRENIC PATIENTS EAT WHEAT?}

Dear Sir,

We have been interested by anecdotal stories about the responses of schizophrenic patients who have taken gluten-free diets and, despite our initial scepticism, are involved in a study of whether there are people who are sensitive in this way to such proteins. In order to study this field a little further, we would be very pleased to receive other anecdotal stories which we could explore more fully to try to find what the patients have in common, if anything, and therefore be more able ourselves to select groups to study.

If people do reply, would they also indicate how far they are willing to allow us to approach such patients.

University of Sheffield Department of Psychiatry

F. A. JENNER

\section{Hallamshire Hospital,}

Glossop Road,

Sheffield S10 2JF.

\section{PSYCHIATRISTS FOR ZAMBIA}

Dear Sir,

Zambia requires psychiatrists for work both in the government service and within the university. Senior, highly experienced colleagues (perhaps having just retired) and those with less experience would be welcome, and posts at a suitable level are available in both service and academic fields. The opportunities for research, teaching and leadership in developing new ideas in community mental health services based upon Primary Health Care will offer a real challenge to those working in either of the closely interlinked sectors.

I shall be attending the College Annual Meeting in Exeter this month and could supply more information then. Alternatively enquiries may be sent to me at the address below.

Institule for African Studies,

Alan Haworth University of Zambia,

PO Box 900

Lusaka, Zambia.

\section{THE PRISON SERVICE}

\section{DeAr SIR,}

The Bulletin of May 1979 has a reference to the dangers of the 'bad institution' ( $p$ 90). Dr Heine, in his letter, also comments on the need to maintain the morale and viability of mental hospitals. In the same issue of the Bulletin is the evidence prepared by the Royal College to the Inquiry into the United Kingdom Prison Service. The Royal College apparently wish to disband the Prison Medical Service and to place the 